Ambiente \& Água - An Interdisciplinary Journal of Applied Science
ISSN 1980-993X - doi:10.4136/1980-993X
www.ambi-agua.net
E-mail: ambi-agua@agro.unitau.br

\title{
Correlação entre qualidade da água e variabilidade da precipitação no sul do Estado do Amapá
}

\author{
doi: 10.4136/ambi-agua.1287
}

Received: 27 Jan. 2014; Accepted: 29 Mar. 2014

\author{
Brunna Stefanny Sangel de Oliveira; Alan Cavalcanti da Cunha* \\ Universidade Federal do Amapá (UNIFAP) Macapá, AP, Brasil \\ Departamento de Meio Ambiente e Desenvolvimento (DMAD) \\ *Autor correspondente: e-mail: alancunha12@gmail.com, \\ brunna_sangel@hotmail.com
}

\section{RESUMO}

O objetivo da investigação foi quantificar a variabilidade da qualidade físico-química e microbiológica da água sob influência da precipitação mensal no Baixo Rio Jari-AP. Este trecho da bacia hidrográfica é considerado como de alto risco às enchentes periódicas. A metodologia de estudo consistiu em coletas mensais de água superficial durante os meses de novembro de 2009 a novembro de 2010, em quatro sítios amostrais definidos em um trecho de $36 \mathrm{~km}$, localizado em frente da cidade Laranjal do Jari-AP. No total, dezesseis parâmetros da qualidade da água foram analisados por amostra. Os resultados foram comparados com as referências do CONAMA 357/2005 (classe 2) e submetidos a uma análise de correlação de Spearman, a qual foi utilizada para quantificar o grau de associação entre parâmetros da qualidade da água e a precipitação mensal. Os parâmetros cor, turbidez, $\mathrm{Al}^{+3}, \mathrm{Mn}^{+2}$ e $E$. coli apresentaram significativa correlação com a precipitação média mensal. Além disso, altas concentrações de DBO e Coliformes Totais (CT) indicaram maior vulnerabilidade ou risco do corpo d'água estar relacionado com doenças potenciais de veiculação hídrica em períodos mais chuvosos. Também, os parâmetros cor, Fe, CT e E. coli apresentaram-se em não conformidade com a legislação CONAMA 357/2005. Concluiu-se que a alteração da qualidade da água tende a se agravar, em termos de vulnerabilidade ou risco à saúde pública, durante eventos mais chuvosos ou de precipitação extrema.

Palavras-chave: monitoramento, bacia hidrográfica, saúde pública, eventos climáticos.

\section{Correlation between water quality and precipitation variability in the Southern State of Amapá}

\begin{abstract}
The objective of this investigation was to quantify the variability of physico-chemical and microbiological water quality parameters under the influence of monthly rainfall in the Lower Jari River, Amapá State. This stretch of the river basin is considered to be at high risk of periodic flooding. The methodology consisted of monthly sampling of surface water from November 2009 to November 2010 at four sampling sites located on a $36 \mathrm{~km}$ stretch in front of Laranjal do Jari City, Amapá. In total, sixteen parameters of water quality were analyzed in each sample. We compared the results with the quality standards of CONAMA Resolution
\end{abstract}


N. 357/2005 for Class 2 rivers using the Spearman Correlation Analysis to quantify the degree of association between water quality parameters and monthly precipitation. The parameters Color, Turbidity, $\mathrm{Al}^{+3}, \mathrm{Mn}^{+2}$ and $E$. coli were significantly correlated with the average monthly rainfall. Furthermore, high concentrations of BOD and Total Coliform (TC) indicated greater vulnerability or environmental risk of potential waterborne diseases is associated with wetter periods. The parameters color, Fe, CT and E. coli were in non-compliance with the CONAMA (357/2005) Resolution. We concluded that water quality tends to deteriorate during wetter periods or extreme rainfall events, resulting in increased vulnerability or risk to public health.

Keywords: monitoring, public health, watershed, climate events.

\section{INTRODUÇÃO}

A presente investigação é parte de um projeto de pesquisa e desenvolvimento (P\&D) realizado exclusivamente para dar suporte às políticas públicas de Defesa Civil e Meio Ambiente na região Sul do Estado do Amapá, especificamente no baixo trecho da Bacia do Rio Jari-AP. O foco principal era subsidiar análises acerca dos riscos sanitários decorrentes de enchentes na referida bacia, especialmente em face das precárias condições sanitárias locais (Oliveira e Cunha, 2014).

Neste contexto, diversas cidades do mundo dispõem de sistemas de esgotos para disposição de águas residuais e, mesmo assim, sofrem sérios problemas de ordem ambiental e de saúde pública, especialmente durante períodos de chuvas intensas quando os esgotos se misturam com águas pluviais. Águas pluviais combinadas com águas residuais sem tratamento na Amazônia é uma severa realidade registrada por pesquisadores da região (Cunha et al. 2004; Miranda et al. 2009; Cunha, 2013).

Por estas razões a mistura de águas residuais com águas pluviais podem degradar severamente a qualidade das águas superficiais receptoras pela modificação de sua função ecológica e pela elevação das concentrações de poluentes minerais, orgânicos e microbiológicos que impactam a saúde pública (Madoux-Humery et al., 2013).

Equipamentos e serviços de saneamento básico podem ser as principais barreiras para reduzir a frequência e a intensidade dos impactos de efeitos de enchentes, principalmente em regiões de alta vulnerabilidade socioambiental sujeitas a enchentes como, por exemplo, na Amazônia (Oliveira e Cunha, 2014).

No Brasil, além do enorme contingente populacional não atendido pelos sistemas de saneamento, os indicadores do IBGE (2010) mostram as desigualdades e os desequilíbrios destes serviços. Dentre os 5.564 municípios brasileiros ainda existem 33 sem estrutura de abastecimento de água e 2.495 sem rede de coleta de esgoto (correspondente a $18 \%$ da população exposta ao risco de contrair doenças em decorrência da inexistência desta rede).

O IBGE (2010) revela que a ausência de saneamento básico acarreta poluição grave dos recursos hídricos, visto que o esgoto é despejado diretamente nos corpos de água sem nenhum tratamento, causando prejuízos à saúde da população e o aumento da mortalidade infantil. Nestes casos, há indícios de que o risco de epidemias tende a ser mais elevado em períodos de cheias (Oliveira e Cunha, 2014; PBMC, 2012). Assim, os problemas de abastecimento de água e saneamento são responsáveis por aproximadamente $80 \%$ de todas as doenças de origem hídrica e mais de um terço das mortes em países em desenvolvimento são causadas pelo consumo de água contaminada (Hespanhol, 2002).

$\mathrm{Na}$ região Norte, esta situação é agravada pelos menores índices de atendimento dos serviços de saneamento básico, apesar dos baixos índices de urbanização em comparação com os da região sul e sudeste (Cunha et al., 2004). Portanto, os impactos da falta de saneamento 
básico e do crescimento urbano acelerado têm sido devastadores do ponto de vista da saúde pública e de problemas de degradação de ecossistemas aquáticos (Hespanhol, 2002).

Deste modo é necessário dispor de regulamentações ambientais mais restritivas para proteger as fontes de água para fins potáveis, priorizando a redução dos efeitos negativos das enchentes com base nos riscos causados ao meio ambiente e à necessidade de prevenção de eventos de chuvas intensas sobre a infraestrutura de saneamento básico.

Segundo Madoux-Humery et al. (2013), por exemplo, indicadores de concentração de bactérias fecais medidas em esgotos variam em ordem de magnitude refletindo as diferenças de duração e intensidade das chuvas, características da bacia de drenagem, procedimentos de amostragem (número e frequência de amostras coletadas) e o tipo de amostras (modo de coleta versus composição). Na literatura há procedimentos que revelam um número de correlações entre parâmetros físico-químicos, metais e indicadores de concentração de bactérias fecais utilizando-se amostras pareadas. Tais correlações podem ser interpretadas para estimar contribuições de águas residuais, pluviais, subterrâneas ou depósitos de esgotos (ressuspensos) refletidos em certos tipos de amostras.

De acordo com Silva et al. (2008), eventos hidrológicos de grande magnitude agravam os problemas sanitários em face da ausência de sistemas de drenagem na região que tornam estas áreas urbanizadas e desorganizadas susceptíveis à precipitação e a má qualidade da água.

No Estado do Amapá a precipitação tem sido um dos fatores relevantes da variabilidade da qualidade da água superficial. Sua importância sanitária e ecológica tem sido estudada há pelo menos uma década (Cunha et al., 2004) indicando existência de correlação entre aumento da precipitação e a elevação do número de coliformes fecais $(\mathrm{CF})$ nos corpos d'água próximos de centros urbanos. Portanto, avaliar efeitos sazonais da precipitação integrados à qualidade da água é importante para compor indicadores de vulnerabilidade e riscos da população em relação ao surgimento de doenças de veiculação hídrica, principalmente em ambientes insalubres.

O município de Laranjal do Jari apresenta um histórico severo e devastador de enchentes causadas pela elevação do nível do rio Jari (Oliveira et al., 2010). A enchente que ocorreu em 2000 foi considerada pela Defesa Civil como a mais grave em danos socioambientais e prejuízos econômicos da história do Estado do Amapá (Rosa et al., 2011). Esse evento prejudicou a zona ribeirinha da cidade alagada por mais de cinco meses no período chuvoso do respectivo ano (Oliveira e Cunha, 2014), expondo a população à situação degradante de condições sanitárias e, consequentemente à vulnerabilidade e à adversidade ambiental.

Neste contexto o objetivo da pesquisa foi avaliar a variação da qualidade físico-química e microbiológica da água do rio Jari em função da variabilidade da precipitação média mensal em um trecho crítico de $36 \mathrm{~km}$ de distância, incluindo-se a cidade de Laranjal do Jari. Como objetivo específico, buscou-se aplicar um método estatístico de correlação entre as variáveis da qualidade da água e a precipitação como uma linha base de conhecimento e interpretação da vulnerabilidade socioambiental e dos riscos hidroclimáticos na referida bacia hidrográfica.

\section{MATERIAL E MÉTODOS}

\section{1. Área de estudo}

A bacia do Rio Jari situa-se na região Amazônica brasileira nas coordenadas geográficas $02^{\circ} 39^{\prime} 02^{\prime \prime}$ ' norte e $01^{\circ} 26^{\prime} 24^{\prime}$ ' sul de latitude e longitude oeste de $51^{\circ} 47^{\prime} 24^{\prime \prime}$ e $55^{\circ} 07^{\prime} 48^{\prime \prime}$ (Figura 1a), com área de drenagem aproximada de $57.000 \mathrm{~km}^{2}$ abrangendo os municípios de Almerim no Pará, e Laranjal do Jari, Vitória do Jari e Mazagão no Amapá. 

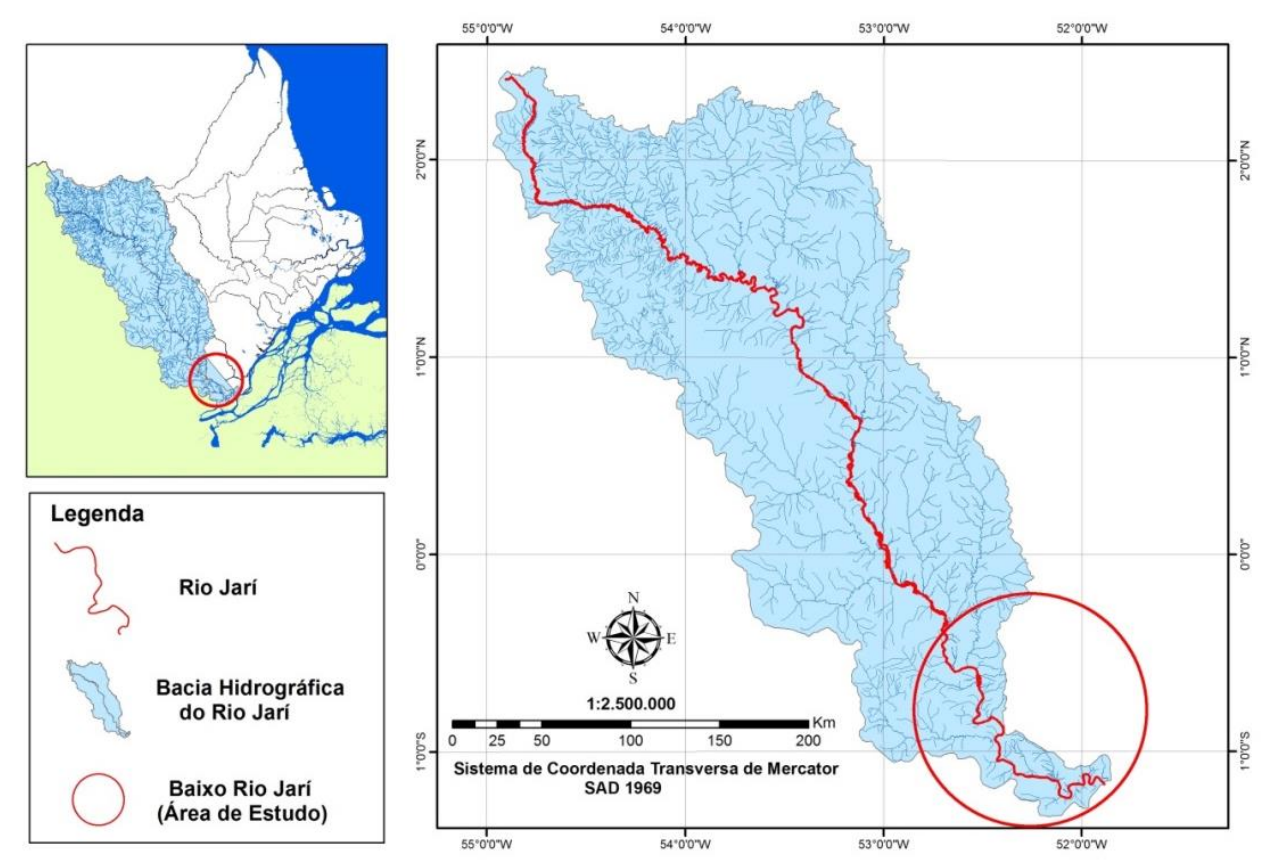

(a)

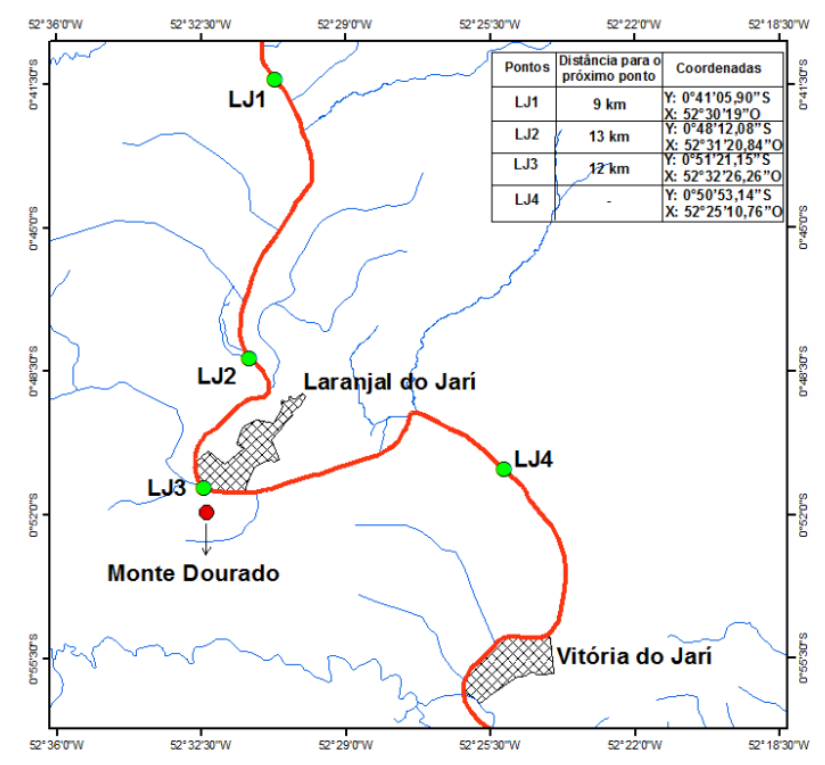

(b)

Figura 1. (a) Mapa da Bacia do Jari, com destaque da área do Baixo Rio Jari; (b) sítios de coleta de água, coordenadas e distâncias entre os sítios amostrais (quadro).

A extensão do canal principal é de aproximadamente $780 \mathrm{~km}$, com a largura máxima de 1 $\mathrm{km}$ e profundidade entre $4 \mathrm{~m}$ nas cheias e 2,4 m na estiagem (Ecology Brasil, 2009). Mas atinge profundidades acima de $25 \mathrm{~m}$ em seu baixo curso. Sua área de drenagem apresenta uma rede hidrográfica relativamente densa, com o curso principal d'água nascendo na Serra do Tumucumaque, na parte setentrional da bacia, divisa com a Guiana Francesa (Hydros Engenharia, 2010) (Figura 1a).

O rio Jari divide os estados do Amapá e Pará e apresenta importância estratégica tanto do ponto de vista social, quanto econômico e ambiental da região. Dentre as principais utilizações do rio destacam-se o abastecimento de água (captação de água) e lançamento de efluentes de esgotos sanitários urbanos in natura das cidades de Laranjal do Jari e Vitória do 
Jari (AP). A exceção é o Distrito de Monte Dourado (PA), município de Almerim, que apresenta sistema de tratamento de esgoto (ETE), um dos casos raros da Amazônia.

Próximo das cidades de Laranjal do Jari, Vitória do Jari e Monte Dourado há empreendimentos industriais de grande porte: Jari Celulose e CADAM (produção de caulim), além da presença de uma Zona Portuária de navegação de calado próximo de 9,5 m.

No trecho inferior do rio (baixo rio Jari), marcado com um círculo vermelho (Figura 1a) destaca-se a área dos sítios de coleta da qualidade da água de $6.769,7 \mathrm{~km}^{2}$ (Figura 1b). Neste trecho estão compreendidos as sedes dos municípios de Laranjal do Jari e Vitória do Jari, e o distrito de Monte Dourado. A principal via de acesso às cidades do sul do Estado do Amapá (Macapá) é a BR-156, estrada de terra que em maior parte do ano apresenta limitações logísticas, onde uma viagem pode variar entre 6 a 12 horas.

\subsection{Procedimento amostral}

Doze coletas de água superficial do rio Jari foram realizadas com frequência mensal no período de novembro de 2009 a novembro de 2010, segundo um cronograma de sazonalidade local caracterizado por dois períodos climáticos: o chuvoso (de janeiro a julho) e o seco (de agosto a dezembro). Foram escolhidos quatro sítios de coleta situados no centro da seção transversal do rio em um trecho de $36 \mathrm{~km}$ (Figura 1b), os quais abrangeram áreas com maior probabilidade de influência sobre as características da água sob impacto da urbanização de Laranjal do Jari. O primeiro sítio (LJ1), localizado a $22 \mathrm{~km}$ a montante da cidade de Laranjal do Jari, o segundo (LJ2) a $12 \mathrm{~km}$, o terceiro (LJ3) em frente à cidade de Laranjal do Jari e o ultimo (LJ4) $12 \mathrm{~km}$ a jusante de Laranjal do Jari.

\subsection{Análise da qualidade da água}

Na Tabela 1 são apresentados dezesseis parâmetros da qualidade da água estudados. São descritos os métodos de análise, as unidades de medida de cada parâmetro medido e os seus valores máximos e mínimos (VMP) permitidos pelas respectivas legislações. A análise dos parâmetros seguiu a metodologia de escolha de reagente, equipamentos, transporte, conservação e análise amostral de acordo com APHA et al. (2003), e os valores foram comparados com os da Resolução n 357 de 2005 do Conselho Nacional do Meio Ambiente (Brasil, 2005), para águas doces de classe dois (classe ainda não enquadrada do Rio Jari), e a Portaria de Potabilidade da Água do Ministério da Saúde no 2.914 de 2011 (para o parâmetro E. coli). Os parâmetros TDS, temperatura, $\mathrm{pH}$, condutividade elétrica e OD foram analisados in loco e os demais em laboratório, a partir da conservação da água em recipientes estéreis sem adição de substâncias para análise da cor; turbidez, TSS e DBO, com adição de ácido nítrico para análise dos metais e ácido sulfúrico para amônia e nitrato; e no recipiente estéril de Colilert (para CF e E. coli), todos transportados em baixa temperatura.

\subsection{Análise hidroclimática e padrão de precipitação}

De acordo com a classificação de Köppen o clima da Amazônia, na qual se inclui a bacia do rio Jari, é do tipo Am. Esta simbologia (A) é consistente com clima tropical chuvoso: no mês mais frio, tomando-se por base a média de vários anos (normalmente 30 anos), a temperatura é superior a $18^{\circ} \mathrm{C}$ (megatérmico) e super úmido. O símbolo $\mathbf{m}$ significa clima de bosque tropical, apesar de existir uma temporada seca (Silveira, 2014).

Segundo Lucas et al. (2010) a Amazônia Oriental, principalmente o Amapá e o Pará, apresentam basicamente dois períodos climáticos característicos. Em um ano climático típico a precipitação do período chuvoso se inicia em dezembro e se estende até maio e a estiagem abrange o período entre setembro e novembro, sendo os demais meses considerados como de transição. O menor volume de chuva mensal acumulado detectado no período climático foi de 11,2 mm em novembro de 2009 e o maior de 482,4 mm, em abril 2010. Esta amplitude de precipitação foi da ordem de 97,6\% quando comparadas ambas as estações, sendo 
representativa da importância da variação climática nas respostas hidrológicas dos rios Amazônicos (Silva et al., 2008; Bárbara et al., 2010; Cunha, 2013; Oliveira e Cunha, 2014).

Os dados de precipitação mensal (referentes a novembro de 2009 a novembro de 2010) para os eventos amostrais da qualidade da água foram obtidos da estação hidrometeorológica de São Francisco (de coordenadas 00³4'04'” sul e 52³4'09' oeste) de código 19150000 da Agência Nacional de Águas (ANA) em operação desde 1968.

Com base nas análises de Lucas et al. (2010) e Silveira (2014) verificou-se que os eventos de precipitação em 2010 foram típicos de padrão climático esperado para a região. Portanto, foram considerados como precipitações normais, sem variações ou influências extremas.

Tabela 1. Unidades de medida dos parâmetros utilizados, e seus respectivos métodos de análise e Valores Máximos e Mínimos (VMP) estipulados pelo CONAMA, Resolução nº 357/2005.

\begin{tabular}{|c|c|c|c|c|}
\hline & Parâmetro & Unidade & Métodos / Equipamento de Análise & $\begin{array}{c}\text { VMP, classe II } \\
\text { (CONAMA, 2005) } \\
\end{array}$ \\
\hline \multirow{6}{*}{ 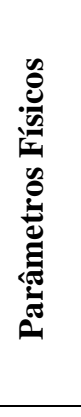 } & Cor & $\operatorname{mgPt~L}{ }^{-1}$ & Espectrofotômetro (Hach Company, 2005) & Máximo $75 \mathrm{mgPt} \mathrm{L}^{-1}$ \\
\hline & Turbidez & NTU & Turbidímetro HACH 2100P & $100 \mathrm{NTU}$ \\
\hline & TSS & $\mathrm{mg} \mathrm{L}^{-1}$ & Espectrofotômetro (Hach Company, 2005) & - \\
\hline & TDS & $\mathrm{mg} \mathrm{L}^{-1}$ & Sonda multiparamétrica & Máximo 500 mg L ${ }^{-1}$ \\
\hline & Temperatura & $\mathrm{C}$ & Sonda multiparamétrica & - \\
\hline & $\begin{array}{l}\text { Condutividade } \\
\text { elétrica }\end{array}$ & $\mu \mathrm{Scm}^{-1}$ & Sonda multiparamétrica & - \\
\hline \multirow{8}{*}{ 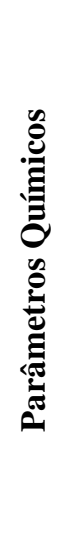 } & OD & $\operatorname{mg~L} L^{-1}$ & Oxímetro 55/YSI & Mínimo $5 \mathrm{mg} \mathrm{L}^{-1}$ \\
\hline & $\mathrm{DBO}_{5,20^{\circ}}$ & $\mathrm{mg} \mathrm{L}^{-1}$ & Método de Winkler & $\mathrm{DBO}_{5,20^{\circ}}$ até $5 \mathrm{mgL}^{-1}$ \\
\hline & $\mathrm{NO}_{3}$ & $\mathrm{mg} \mathrm{L}^{-1} \mathrm{~N}$ & NitraVer (Hach Company, 2005) & Máximo $1 \mathrm{mg} \mathrm{L}^{-1}$ \\
\hline & $\mathrm{NH}_{3}$ & $\mathrm{mg} \mathrm{L}^{-1} \mathrm{~N}$ & (Hach Company, 2005) & Máximo $3,7 \mathrm{mg} \mathrm{L}^{-1}$ \\
\hline & $\mathrm{pH}$ & - & pH-âmetro Orion/3 Star & Entre 6 e 9 \\
\hline & $\mathrm{Fe}^{+}$ & $\operatorname{mg~L} \mathrm{Le}^{-1}$ & FerroVer (Hach Company, 2005) & Máximo $0,3 \mathrm{mg} \mathrm{L}^{-1}$ \\
\hline & $\mathrm{Al}^{+}$ & $\mathrm{mg} \mathrm{L}^{-1} \mathrm{Al}^{+3}$ & AluVer (Hach Company, 2005) & Máximo $0,1 \mathrm{mg} \mathrm{L}^{-1}$ \\
\hline & $\mathrm{Mn}^{+}$ & $\mathrm{mg} \mathrm{L}^{-1} \mathrm{Mn}^{+2}$ & PAN (Hach Company, 2005) & Máximo $0,1 \mathrm{mg} \mathrm{L}^{-1}$ \\
\hline \multirow{2}{*}{ 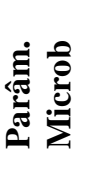 } & $\mathrm{CT}$ & $\begin{array}{l}\text { CT / } 100 \mathrm{ml} \mathrm{de} \\
\text { água }\end{array}$ & $\begin{array}{l}\text { Substrato cromogênico com } \\
\text { Colilert/IDEXX }\end{array}$ & $\begin{array}{l}\text { Máximo } 1000 \text { em } \\
100 \mathrm{ml} \text { de água }\end{array}$ \\
\hline & E.coli & $\begin{array}{l}\text { E.coli/ } 100 \mathrm{ml} \mathrm{de} \\
\text { água }\end{array}$ & $\begin{array}{l}\text { Substrato cromogênico com } \\
\text { Colilert/IDEXX }\end{array}$ & $\begin{array}{l}\text { Ausência em } 100 \mathrm{ml} \\
\text { de água }\end{array}$ \\
\hline
\end{tabular}

Nota: o VMP de E. coli utilizado como referência foi retirado da Portaria do Ministério da Saúde no 2.914 de 2011 , visto que a água do rio Jari é frequentemente consumida pela população ribeirinha in natura, independentemente da Estação de Tratamento de Água (ETA).

\subsection{Análise estatística da qualidade da água do rio Jari}

Para verificação do grau de dispersão dos valores dos parâmetros medidos em relação à média, utilizou-se o desvio padrão como referência tanto espacial (distância entre sítios amostrais) quanto temporal (mensal), e intervalo de confiança de $95 \%$.

A avaliação do nível de correlação entre a precipitação e os parâmetros físico-químicos e microbiológicos foi realizada com o teste estatístico de correlação de Spearman, usando o Software Statistica 6.0. Em resumo, a análise de correlação quantifica o grau de associação 
entre duas ou mais variáveis mensuradas pelo coeficiente " $r$ ", sendo convencionalmente significativo quando $r \geq 0,60$ ( $p<0,05$ ) (Hand, 2008).

O grau de associação entre os parâmetros da qualidade da água e os níveis de precipitação médios entre as estações climáticas característica da região foi quantificada pela precipitação média mensal, usada como a variável independente, e os parâmetros da qualidade da água, como variáveis dependentes. A hipótese considerada é que a correlação foi determinada pela precipitação como principal variável explicativa da alteração ou variação dos parâmetros da qualidade da água no período. O produto final da análise é uma matriz de correlação de Spearman, vez que as variáveis não são de uma distribuição normal.

\section{RESULTADOS E DISCUSSÃO}

\subsection{Comportamento dos parâmetros e compatibilidade com a legislação}

\subsubsection{Parâmetros físicos}

As características físicas de um corpo d'água normalmente estão relacionadas aos aspectos de ordem estética, cujos valores extremos podem causar repugnâncias perceptíveis aos sentidos humanos. A característica física da água que apresentou alterações ao longo do monitoramento foi a Cor (Figura 2). Este parâmetro apresentou-se acima do limite máximo permitido (de $75 \mathrm{mgPtL}^{-1}$ ) em 73,33\% das amostras, variando de $21 \mathrm{mg} \mathrm{PtL}^{-1}$ (novembro de 2009) a $163 \mathrm{mg} \mathrm{PtL}^{-1}$ (maio de 2010), ambos encontrados no sítio LJ1 (22 km a montante da cidade de Laranjal do Jari) e 68,18 \% destes registrados no período chuvoso. Concentrações superiores deste parâmetro causam não só alterações estéticas na água, mas interferem nos processos biogeoquímicos, especialmente na fotossíntese, pelo impedimento da passagem de luz no meio aquático (Bárbara et al., 2010).

A turbidez da água apresentou-se abaixo do limite máximo estipulado pelo CONAMA, de 100 NTU. Este comportamento também pode ser observado em concentrações de sólidos em suspensão (TSS) (Figura 2). Os sólidos suspensos, que englobam substâncias sólidas com diâmetro superior a $1 \mu$ (Vasco et al., 2011), não apresentam valores máximos estipulados pela CONAMA, mas seus valores interferem no comportamento da turbidez, como pode se observar no rio Jari, apresentando influência nos ecossistemas aquáticos, tanto na fotossíntese quanto na dinâmica hidrossedimentométrica (Bárbara et al., 2010).

A temperatura da água é um dos parâmetros mais importantes da qualidade da água. Influencia as taxas e os processos biogeoquímicos, além de controlar o consumo de nutrientes (Ward et al., 2013) e, portanto, a dinâmica de espécies aquáticas dependentes destes últimos. A Temperatura da água do rio Jari variou de $25,0{ }^{\circ} \mathrm{C}$ a $29,98{ }^{\circ} \mathrm{C}$, sendo esta suave amplitude observada a partir do período chuvoso para o de estiagem (Figura 2). Contudo, nos últimos 40 anos de observação da temperatura na Amazônia (PBMC, 2012; Silveira, 2014) nota-se uma suave tendência de redução das precipitações e elevação de temperatura na atmosfera. Contudo, esta variação pode estar associada a uma segunda fonte de incerteza, isto é, o momento de coleta (hora do procedimento), que varia em relação ao período sazonal climático de grandes e pequenas escalas (Miranda et al., 2009).

Em relação à condutividade elétrica da água, que depende diretamente da temperatura, não houve variações significativas (Figura 2), tanto em termos espaciais quanto temporais. A exceção foi o mês de maio, com os menores valores, em torno de $21 \mu \mathrm{S} \mathrm{cm}^{-1}$, provavelmente devido ao efeito de diluição causado pelo deflúvio de maior volume de chuva.

Ainda em relação à Figura 2, em geral, é comum na região amazônica características de elevadas concentrações (Cor) e baixas concentrações de Sólidos Suspensos (SS), e consequentemente de Turbidez. A Cor da água nesta região é influenciada principalmente por compostos inorgânicos e orgânicos (substâncias húmicas) presentes no solo, como óxidos de 
ferro (ou óxido de manganês), que apresentam características coloidais que alteram a cor da água mas não influenciam na Turbidez (Bárbara et al., 2010; Cunha, 2013).
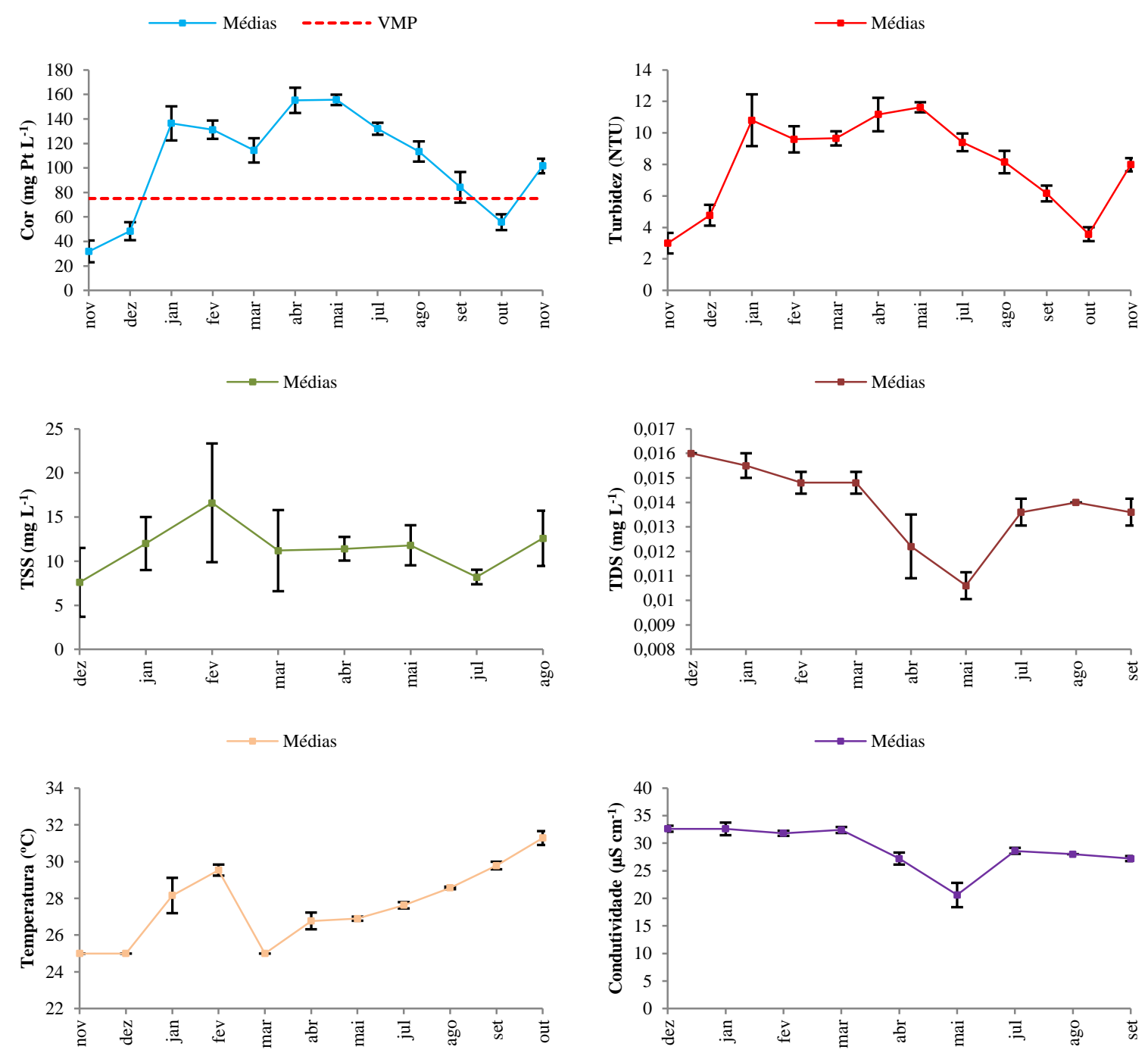

Figura 2. Variação das médias mensais dos parâmetros cor, turbidez, TSS, TDS, temperatura e condutividade elétrica. Em destaque os respectivos desvios padrão entre os sítios de coleta (LJ1, LJ2, LJ3 e LJ4) e o valor máximo permitido (VMP) pelo CONAMA (Resolução 357/2005) apenas para o parâmetro Cor. Período entre novembro de 2009 e janeiro de 2010.

\subsubsection{Parâmetros químicos}

Os parâmetros químicos são associados a potenciais fontes de poluição que são indicadores do equilíbrio biogeoquímico necessário à manutenção da vida aquática. Dentre os quais se destacam o Oxigênio Dissolvido (OD), Demanda Bioquímica de Oxigênio $\left(\mathrm{DBO}_{5,20^{\circ} \mathrm{C}}\right)$, nitrato $\left(\mathrm{NO}_{3}\right)$, amônia $\left(\mathrm{NH}_{3}\right), \mathrm{pH}$, ferro $\left(\mathrm{Fe}^{+2}\right)$, alumínio $\left(\mathrm{Al}^{+3}\right)$ e manganês $\left(\mathrm{Mn}^{+2}\right)$ (Figura 3).

A concentração de OD na água do rio Jari apresentou-se dentro dos limites do CONAMA ( $\geq 5 \mathrm{mg} \mathrm{L}^{-1}$ ) (Figura 3), com exceção da amostra de setembro em LJ3 (4,56 mgL ${ }^{-1}$ ), em frente da cidade de Laranjal do Jari. A concentração de OD na água observado no segundo semestre de 2010, durante a estiagem, em primeiro lugar pode estar sendo influenciada pelo aumento das concentrações de matéria orgânica biodegradável (DBO), encontrada em frente da cidade. Assim, tende a interferir no processo de autodepuração da água e consequentemente causar depleção do OD (Gonçalves et al., 2012). Em segundo lugar, o aumento da temperatura no 
período de estiagem reduz a concentração de saturação de OD (Alvarenga et al., 2012; Bárbara et al., 2010). Como a concentração de OD é inversamente proporcional à temperatura da água, naturalmente esta tende a diminuir durante a estiagem devido a maior intensidade de radiação solar sobre o corpo d'água reduzindo sua solubilidade.
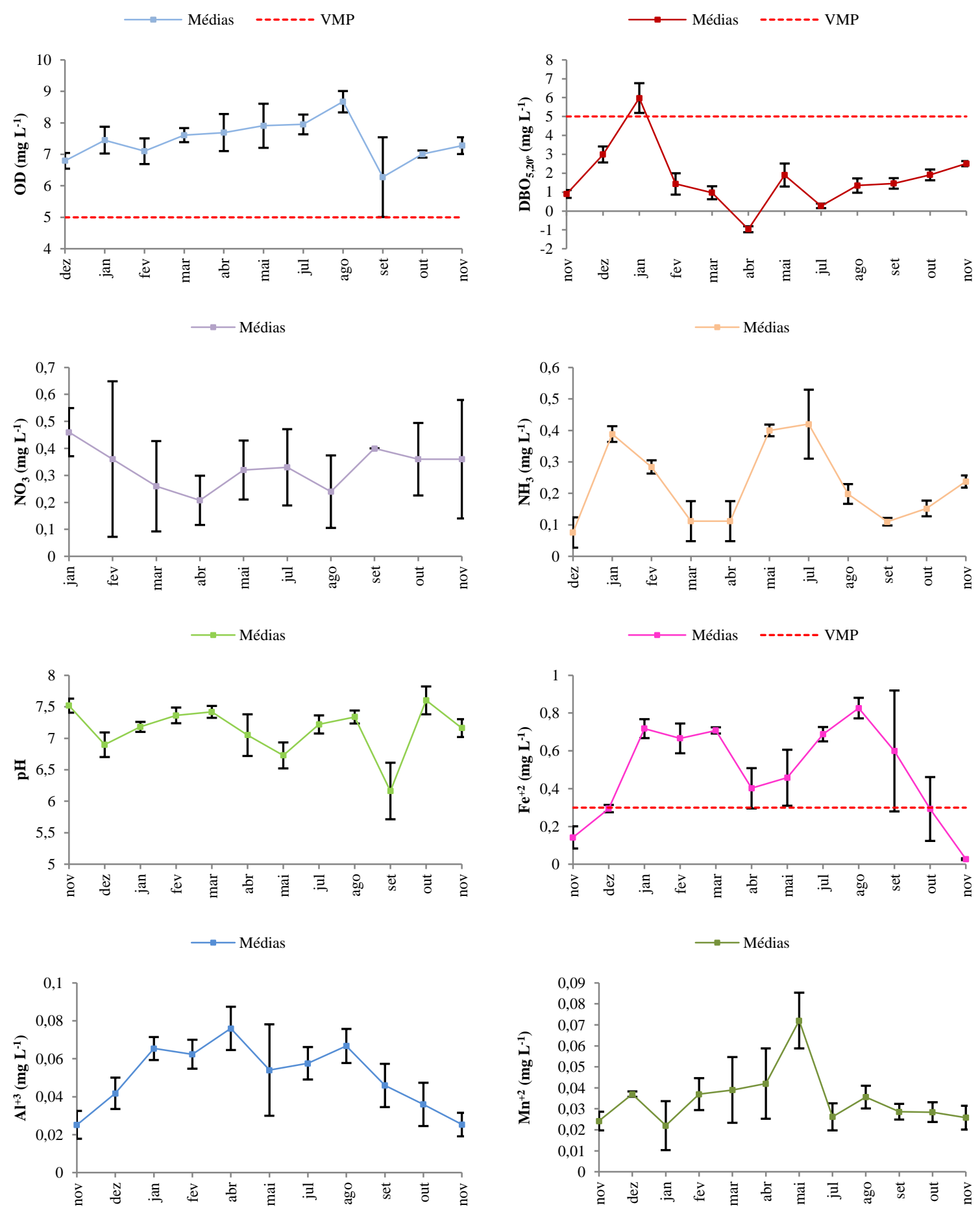

Figura 3. Variação das médias mensais dos parâmetros Oxigênio Dissolvido (OD), Demanda Bioquímica de Oxigênio $\left(\mathrm{DBO}_{5,20^{\circ} \mathrm{C}}\right)$, nitrato $\left(\mathrm{NO}_{3}\right)$, amônia $\left(\mathrm{NH}_{3}\right)$, pH, ferro $\left(\mathrm{Fe}^{+2}\right)$, alumínio $\left(\mathrm{Al}^{+3}\right)$ e manganês $\left(\mathrm{Mn}^{+2}\right)$. Em destaque os respectivos desvios padrão da variação espacial entre os sítios de coleta (LJ1, LJ2, LJ3 e LJ4)e o valor mínimo de OD e máximo de $\mathrm{DBO}_{5,20^{\circ}}$ e $\mathrm{Fe}^{+2}$ permitido (VMP) pelo CONAMA (Resolução 357/2005). Período entre novembro de 2009 e janeiro de 2010. 
A DBO também se apresentou abaixo do limite do CONAMA $\left(\leq 5 \mathrm{mg} \mathrm{L}^{-1}\right)$, com exceção dos sítios LJ1, LJ3 e LJ4 no mês de janeiro $\left(7 \mathrm{mg} \mathrm{L} \mathrm{L}^{-1}, 6,3 \mathrm{mg} \mathrm{L}^{-1}\right.$ e $5,6 \mathrm{mg} \mathrm{L}^{-1}$, respectivamente), no início do período chuvoso. Este parâmetro é uma medida indireta da quantidade de matéria orgânica respirável presente na água e também é um indicador do potencial de emissões de gases de efeito estufa dos rios para atmosfera (Ward et al., 2013). Representa a demanda OD natural da bacia e principalmente a de origem de lançamento de esgotos in natura. Portanto, a DBO pode ser de origem pontual ou difusa e pode causar desequilíbrio biogeoquímico nos ecossistemas (Hespanhol, 2002). No presente caso, a zona urbana de Laranjal do Jari não apresenta nenhum tipo de sistema de tratamento de efluentes, sendo estes lançados sem tratamento no rio Jari (Vasco et al., 2011; Oliveira e Cunha, 2014). Em relação ao $\mathrm{NO}_{3}$ e $\mathrm{NH}_{4}{ }^{+}$observou-se conformidade de concentrações, indicando sistemas com comportamento oligotrófico, tal como ocorre no rio Araguari-AP (Bárbara et al., 2010).

Os parâmetros $\mathrm{OD}$ e a $\mathrm{DBO}$ são diretamente relacionados à qualidade do ecossistema aquático, dependentes da carga de resíduos (esgotos urbanos ou industriais), mas suas variações também refletem uma potencial resposta da capacidade autodepurativa dos corpos d'água (Cunha et al., 2004; Ward et al., 2013; Cunha, 2013). Em ambientes com pouco OD e elevada quantidade de matéria orgânica (DBO) tornam-se propícios ao desenvolvimento de organismos mais adaptados a estas condições, mas com tendência à perda de biodiversidade aquática (Alvarenga et al., 2012; Bárbara et al., 2010). Além disso, além de dificultar os processos autodepurativos do rio, impossibilitama sobrevivência de espécies aquáticas mais exigentes ao oxigênio (Giovanna e Cunha-Santino, 2013; Madoux-Humery et al., 2013).

Como foi observado na Figura 3, os valores dos nutrientes $\mathrm{NO}_{3}$ e $\mathrm{NH}_{3}$ não ultrapassaram o VMP (CONAMA 357/2005) em nenhuma das amostras. A concentração de $\mathrm{NO}_{3}$ se elevou em alguns sítios, como LJ2 em janeiro (Figura 3), em fevereiro e março no sítio em frente a cidade (LJ3) e em julho e novembro (LJ1, $22 \mathrm{~km}$ a montante de Laranjal do Jari). Esses valores dependem de processos de lixiviação de matéria orgânica do solo para a água em decorrência das chuvas e estão relacionados com processos bioegeoquímicos mais tardios.

$\mathrm{O}$ parâmetro $\mathrm{pH}$ não apresentou variações significativas em relação aos sítios de coleta, com exceção do mês de setembro em LJ3, com valor igual a 5,61 e LJ2 com valor de 5,88. Ambos abaixo do valor mínimo permitido pelo CONAMA (357/2005), isto é pH =6,0.

Em relação ao parâmetro químico ferro $\left(\mathrm{Fe}^{+2}\right)$ observou-se valores de concentração superiores ao VMP em $88 \%$ das amostras (valor máximo de $0,3 \mathrm{mgL}^{-1}$ ) (Figura 3). O ferro, quando em altas concentrações, apesar de não ser considerado um Elemento Potencialmente Tóxico (EPT), pode causar alterações na cor da água, manchando objetos e interferir no sistema de abastecimento (Bárbara et al., 2010). Contrariamente, os demais metais alumínio $\left(\mathrm{Al}^{+2}\right)$ e manganês $\left(\mathrm{Mn}^{+2}\right)$ mantiveram-se dentro do limite do CONAMA de $0,1 \mathrm{mg} \mathrm{L}^{-1}$.

\subsubsection{Parâmetros microbiológicos}

As concentrações de Coliformes Totais (CT) estavam acima do limite máximo do CONAMA (máxima de 1.000 Coliformes/100 ml de água) em $70 \%$ das amostras, indicando que neste trecho do rio Jari estas concentrações são elevadas (Figura 4), mas suas fontes têm sido pouco estudadas. Contudo, este padrão e níveis de concentração têm sido frequentes em rios da Amazônia, mesmo em zonas rurais sem fontes de poluição explícitas, provavelmente devido às características biológicas dos solos e presença de florestas, sendo difícil identificar se as fontes são exclusivamente de origem natural ou antropogênica (Hespanhol, 2002; Cunha et al., 2004; Silva et al., 2008; Miranda et al., 2009; Ward et al., 2013; Cunha 2013).

De acordo com a Figura 4 as concentrações de CT elevadas foram observadas em todos os sítios de coleta. Os maiores desvios padrão em relação às médias foram devidos à diferença entre valores dos meses de novembro e dezembro de 2009. Verificou-se que em LJ1 e LJ3 ocorreram as concentrações mais altas, enquanto que em LJ2 e LJ4 as mais reduzidas. Mas 
nos meses de janeiro, fevereiro e março de 2010 o sítio em frente à cidade (LJ3) apresentou os maiores teores de CT, justificando-se a importância do efeito e os riscos da urbanização quanto às fontes de CT. Assim, é possível estimar que a principal fonte de contaminação pode ser de origem antropogênica, ou de despejos urbanos de esgoto in natura nesta localização.
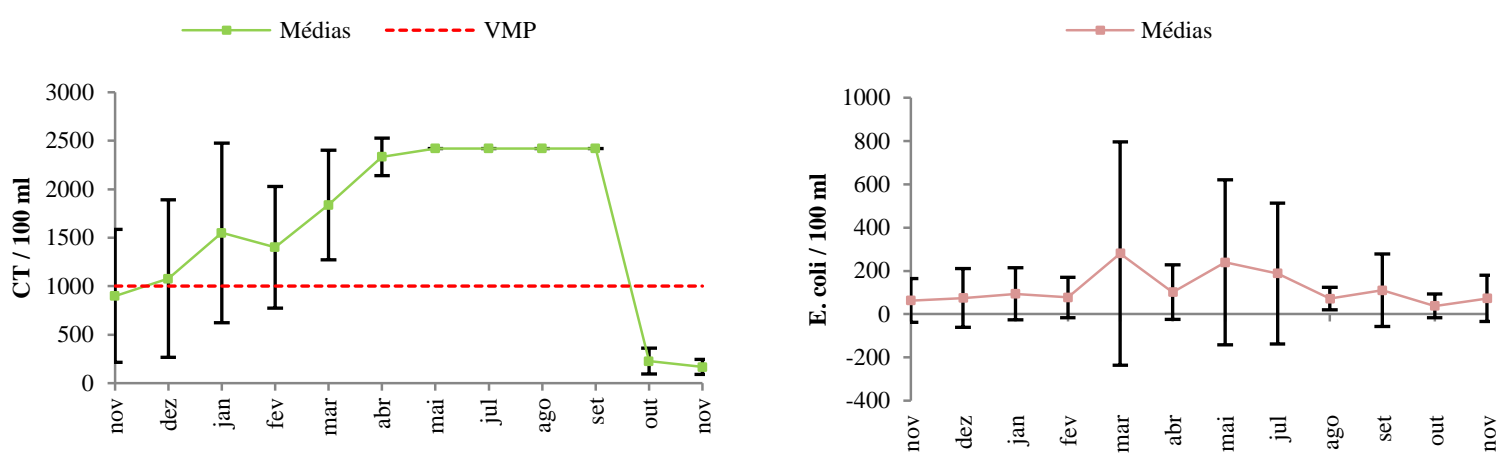

Figura 4. Variação das médias mensais dos parâmetros Coliformes Totais (CT) e Escherichia Coli (E.coli). Em destaque os respectivos desvios padrão entre ossítios de coleta (LJ1, LJ2, LJ3 e LJ4) e o valor máximo (VMP) pelo CONAMA (Resolução 357/2005) de CT. Período entre novembro de 2009 a janeiro de 2010.

Além disso, observa-se que a concentração de CT não segue uma distribuição contínua ao longo do trecho estudado, pois as concentrações se elevam em sítios intermitentes, provavelmente influenciados pelo padrão "caótico" de lançamento de fontes pontuais e difusas de esgoto in natura, ao mesmo tempo em que ocorrem influências naturais comentadas anteriormente, devido a presença natural destas bactérias no solo. Contudo, na Figura 4, destacam-se as concentrações presentes nos sítios próximos aos sítios LJ1 e LJ3.

Ainda na Figura 4, em relação a E.coli, a Portaria 2.914 de 2011 do Ministério da Saúde limita o consumo humano de água isenta desta bactéria de origem fecal (após tratamento convencional). Como a água do rio Jari é utilizada para abastecimento público de Laranjal do Jari e de Monte Dourado (e às vezes sem nenhum tratamento, captada diretamente na beira do rio por comunidades ribeirinhas), as concentrações foram consideradas muito acima do esperado, com os maiores valores encontrados no sítio em frente à cidade de Laranjal do Jari (LJ3). Felizmente este sítio está a jusante da captação da cidade. E, no mês de março (período muito chuvoso $\approx 450 \mathrm{~mm}$ ), este local não dispõe de nenhuma infraestrutura de tratamento de resíduos domésticos.

Por outro lado, a presença desta bactéria não indica diretamente a presença de patogênicos, mas é uma boa estimativa da probabilidade de ocorrência deste tipo de organismo, haja vista que os microrganismos nocivos à saúde humana se alojam no intestino de indivíduos contaminados e são eliminados através de suas fezes (Cunha et al., 2004).

\subsection{Matriz de Correlação de Spearman- Qualidade da Água $x$ Precipitação}

A análise de correlação foi utilizada a partir das médias aritméticas dos parâmetros medidos nos sítios de coleta. Foram identificados os parâmetros Cor, Turbidez, Alumínio, Manganês e E. coli com correlação positiva em relação à precipitação. Ou seja, menores valores de concentração no período de estiagem e maiores no período chuvoso. Portanto, estes parâmetros variaram significativamente no trecho nos diferentes meses de coleta, tendendo a oscilar ainda mais em eventos extremos de cheia na região do sul do Estado do Amapá. A Tabela 2 mostra os valores de correlação (Spearman) significativos destacados nos campos pela cor cinza ( $p$-valor $<0,005)$.

De acordo com a Tabela 2, em termos gerais, as variações de Cor, Turbidez, Al, Mn e $E$. coli podem ser explicadas pelas variações de precipitação. Contudo, observa-se que os 
parâmetros $\mathrm{CT}$ e E. coli devem ser considerados como os mais relevantes em razão de sua importância sanitária e de saúde pública. Estes realmente se destacam mais em eventos de cheias extremas, haja vista que os riscos epidemiológicos tendem a ser maiores nestes períodos devido ao maior número de alagamentos na bacia (Oliveira e Cunha, 2014).

Por outro lado, a variação da concentração de CT não foi significativamente explicada pela variação da precipitação, mas sua significância ficou próxima do limite $(p=0,068)$.

Em relação aos parâmetros físicos, observa-se que Cor e Turbidez sofrem influência significativa da precipitação, intensificando-se nos períodos chuvosos. Estes parâmetros, se deteriorados, contudo tendem a comprometer mais as condições sanitárias, especialmente as relacionadas ao abastecimento de água (captação, como custo de tratamento).

Tabela 2. Teste de correlação de Spearman (parâmetro da qualidade da água x precipitação).

\begin{tabular}{|c|c|c|c|c|}
\hline \multirow[t]{2}{*}{ Par de variáveis } & \multicolumn{4}{|c|}{$\begin{array}{c}\text { Ordenamento em Ranks -Correlações de Spearmane } \\
\text { Significância em } p<0,050\end{array}$} \\
\hline & $N$ (amostras) & Spearman $R$ & $\boldsymbol{t}_{(N-2)}$ & Nivel-p $(<0,05)$ \\
\hline Precipitação $x$ Cor & 12 & $0,812611 *$ & 4,40918 & 0,001316 \\
\hline Precipitação $x$ Turbidez & 12 & $0,868653^{*}$ & 5,54462 & 0,000246 \\
\hline Precipitação $x$ TSS & 8 & $-0,309524$ & $-0,79733$ & 0,455645 \\
\hline Precipitação $x$ TDS & 9 & 0,122364 & 0,32620 & 0,753812 \\
\hline Precipitação $x$ Temper. & 11 & $-0,386216$ & $-1,25611$ & 0,240702 \\
\hline Precipitação $x$ Condut. & 9 & $-0,130803$ & $-0,34907$ & 0,737301 \\
\hline Precipitação $x$ OD & 11 & $-0,437459$ & 1,45902 & 0,178561 \\
\hline Precipitação $x \mathrm{NO}_{2}$ & 10 & $-0,104620$ & $-0,29754$ & 0,773633 \\
\hline Precipitação $x \mathrm{NH}_{3}$ & 10 & 0,189024 & 0,54446 & 0,600969 \\
\hline Precipitação $x \mathrm{pH}$ & 11 & $-0,464694$ & $-1,57439$ & 0,149849 \\
\hline Precipitação $x \mathrm{Fe}$ & 12 & 0,451840 & 1,60166 & 0,140313 \\
\hline Precipitação $x \mathrm{Al}$ & 11 & $0,724375^{*}$ & 3,15217 & 0,011697 \\
\hline Precipitação $x \mathrm{Mn}$ & 12 & $0,633975^{*}$ & 2,59236 & 0,026841 \\
\hline Precipitação $x$ DBO & 12 & $-0,182137$ & $-0,58577$ & 0,571016 \\
\hline Precipitação $x \mathrm{CT}$ & 12 & 0,541959 & 2,03929 & 0,068729 \\
\hline Precipitação $x$ E. coli & 12 & $0,777584 *$ & 3,91066 & 0,002910 \\
\hline
\end{tabular}

* significativo $(\mathrm{p}<0,05)$.

Os parâmetros químicos, como a variação de $\mathrm{Al}$ e Mn, também se apresentaram com influência significativa em relação à precipitação. Ambos seguiram o mesmo padrão de comportamento ao longo das variações mensais. Entretanto, altos valores de concentração de Al representam mais riscos em termos de toxicidade para o abastecimento público, pois são neurotóxicos.

\section{CONCLUSÃO}

A presente investigação é uma análise objetiva sobre a variação de parâmetros da qualidade da água em um trecho do rio Jari e sua relação com fatores hidroclimáticos (precipitação). A investigação mostrou que os parâmetros Cor, Ferro, CT e E. coli sofrem influência significativa da precipitação, sendo esta última uma forçante natural importante sobre a ecossistêmica e as condições sanitárias locais, independentemente do tipo de fonte de poluição, se pontuais ou difusas.

As concentrações dos parâmetros Cor, Ferro, CT e E. coli foram observados acima dos valores máximos permitidos pela Resolução CONAMA (357/2005). Assim, há fortes indícios 
de alteração da qualidade da água por lançamento de esgoto doméstico in natura no manancial, especialmente em frente da Cidade de Laranjal do Jari, apesar de sua elevada vazão média, da ordem de $2000 \mathrm{~m}^{3} \mathrm{~s}^{-1}$.

A Matriz de Spearman representa uma técnica sintética interessante no auxílio de estratégias de monitoramento e gerenciamento da qualidade da água no rio Jari. Mas é importante ressaltar que somente foi possível utilizar a Matriz de Spearman porque entre 2009 e 2010 as precipitações foram consideradas climatologicamente normais. Deste modo, é necessário antes verificar esta condição, para afirmar se a explicabilidade $\left(\mathrm{R}^{2}\right)$ da variação da Cor, Turbidez, Al e Mn e E. coli com a precipitação é significativa. Esta hipótese é importante porque torna a análise dos indicadores mais confiável em relação ao monitoramento e, consequentemente, mais útil como subsídio ao gerenciamento de riscos, planejamento de recursos hídricos e monitoramento de variáveis sanitárias no referido trecho da bacia.

Deste modo a quantificação de CT e E. coli serviu como indicadora do risco potencial da presença de agentes patogênicos na água ao longo do ano. Assim, a vulnerabilidade sanitária a que a população de Laranjal do Jari está sujeita pode ser estimada com base nos respectivos parâmetros microbiológicos medidos, mas com base nas condições de precipitação média do mês atual ou anterior, as quais são mais facilmente monitoráveis e previsíveis. Com efeito, em eventos climatológicos extremos, espera-se maior nível de deteriorização da qualidade da água em todas as três dimensões (física, química e microbiológica), sendo a presente análise facilmente utilizada como uma medida de referência básica da vulnerabilidade ou risco de contaminação futuras na bacia.

\section{AGRADECIMENTOS}

Agradecemos o apoio financeiro do projeto "Rede de Gestão Integrada de Monitoramento da Dinâmica Hidroclimática e Ambiental do Estado do Amapá". Convênio: 702813 - SUDAM e o Núcleo de Hidrometeorologia e Energias Renováveis (NHMET/IEPA) e ao Laboratório de Química, Saneamento e Modelagem de Sistemas Ambientais (LAMSA/UNIFAP) e ao Centro de Estudos Integrados da Biodiversidade Amazônica (CENBAM-INPA/CNPq).

\section{REFERÊNCIAS}

ALVAREnGA, L. A.; MARTins, M. P. P.; CUARTAS, L. A.; PENTEADO, V. A.; ANDRADE, A. Estudo da qualidade e quantidade da água em microbacia, afluente do rio Paraíba do Sul - São Paulo, após ações de prevenção ambiental. Revista Ambiente \& Água, Taubaté, v. 7, n. 3, p. 228-240, 2012. http://dx.doi.org/10.4136/ambi-agua.987

AMERICAN PUBLIC HEALTH ASSOCIATION - APHA; AMERICAN WATER WORKS ASSOCIATION - AWWA; WATER POLLUTION CONTROL FACILITIES WPCF. Standard methods for examination of water and wastewater. $20^{\text {th }}$ Edition. Washington, D.C., 2003.

BÁRBARA, V. F.; CUNHA, A. C.; SIQUEIRA, E. Q. Monitoramento sazonal da qualidade da água do rio Araguari/AP. Revista de Biociências, UNITAU, v. 16, n. 1, p. 57-72, 2010 .

BRASIL. Conselho Nacional do Meio Ambiente - CONAMA. Resolução No 357, de 17 de março de 2005. Classificação dos corpos de água e diretrizes ambientais para o seu enquadramento, estabelecimento das condições e padrões de lançamento de efluentes e outras providências. Diário Oficial [da] União, Brasília, DF, 18 mar. 2005, Seção 1, p. 58-63. 
CUNHA, A. C; CUNHA, H. F. A.; BRASIL JR., A. C. P; DANIEL, L. A; SCHULZ, H. E. Qualidade microbiológica da água de rios de áreas urbanas e periurbanas no baixo Amazonas: o caso do Amapá. Revista de Engenharia Sanitária e Ambiental, Rio de Janeiro, v. 9, n. 4, p. 322-328, 2004.

CUNHA, A. C. Revisão descritiva sobre ecossistemas aquáticos na perspectiva da modelagem da qualidade da água. Biota Amazônia, v. 3, p. 124-143, 2013.

ECOLOGY BRASIL. Compêndio do estudo de impactos ambientais para construção da Usina Hidrelétrica (UHE) de Santo Antônio do Jari. Amapá, 2009. 570 p.

GIOVANNA, G. M.; CUNHA-SANTINO, M. B. Análise e diagnóstico da qualidade da água e estado trófico do reservatório de Barra Bonita (SP). Revista Ambiente \& Água, Taubaté, v. 8, n. 1, p. 186-205, 2013. http:/dx.doi.org/104136/ambi-agua.930

GONÇALVES, J. C. S. L.; SARDINHA, D. S.; SOUZA, A. D. G.; DIBIAZI, A. L. B.; GODOY, L. H.; CONCEIÇÃO, F. T. Avaliação espaço-temporal da qualidade da água e simulação de autodepuração na bacia do córrego São Simão, SP. Revista Ambiente \& Água, Taubaté, v. 7, n. 3, p. 141-154, 2012. http://dx.doi.org/10.4136/ambi-agua.894

HACH COMPANY. DR/2800 Espectrofotometer. Procedures Manual. 1. ed. Loveland, 2005 .

HAND, D. J. Statistics: a very short introduction. Oxford: Oxford University Press, 2008.

HESPANHOL, I. Água e saneamento básico - uma visão realista. In: CUNHA, A. R.; BRAGA, B.; TUNDISI, J. G. (Orgs.). Águas doces no Brasil: capital ecológico, uso e conservação. 2. ed. São Paulo: Escrituras, 2002.

INSTITUTO BRASILEIRO DE GEOGRAFIA E ESTATÍSTICA - IBGE. Censo demográfico 2010. 2010. Disponível em: http://censo2010.ibge.gov.br. Acesso em: 20 ago. 2012.

HYDROS ENGENHARIA. Inventário hidroenergético da bacia hidrográfica do Rio Jari / PAAP. Empresa de Pesquisa Energética. [S.1.], junho de 2010.

LUCAS, E. W. M.; BARRETO, N. J. C.; CUNHA, A. C. Variabilidade hidrológica da Bacia do Rio Jari (AP): estudo de caso do ano 2000. In: Tempo, Clima e Recursos Hídricos: resultados do Projeto REMETAP no Estado do Amapá. Macapá: IEPA, 2010. p. 119-134.

MADOUX-HUMERY, A. S.; DORNER, S.; SAUVÉ, S.; ABOULFADL, K.; GALARNEAU, M.; SERVAIS, P. et al. Temporal variability of combined sewer overflow contaminants: Evaluation of wastewater micropollutants as tracers of fecal contamination. Water Research, n. 47, p. 4370-4382, 2013. http://dx.doi.org/ 10.1016/j.watres.2013.04.030

MIRANDA, R. G.; PEREIRA, S. F. P.; ALVES, D. T. V.; OLIVEIRA, G. R. F. Qualidade dos recursos hídricos da Amazônia - Rio Tapajós: avaliação de caso em relação aos elementos químicos e parâmetros físicos-químicos. Revista Ambiente \& Água, Taubaté, v. 4, n. 2, p. 75-92, 2009. http://dx.doi.org/10.4136/ambi-agua.88

OLIVEIRA, A. D.; CUNHA, A. C. Análise de risco como medida preventiva de inundações na Amazônia: estudo de caso da enchente de 2000 em Laranjal do Jari-AP, Brasil. Revista Ciência \& Natura, jan./mar. 2014, edição especial (in press). 
OLIVEIRA, A. M.; CUNHA, A. C; SANGEL, B.; SANTOS, K. P. C. Eventos hidroclimáticos extremos no município de Laranjal do Jari-AP: uma análise jurídicoeconômica das enchentes de 2000 e 2006. In: CONGRESSO BRASILEIRO DE METEOROLOGIA, 16., 2010, Belém. Proceedings... Rio de Janeiro: SBMET, 2010.

PAINEL BRASILEIRO DE MUDANÇAS CLIMÁTICAS (PBMC). Base Científica das Mudanças Climáticas. Sumário executivo do volume 1. Rio de Janeiro, 2012. 34 p.

ROSA, A. F. M.; MIERES, L. S.; SALDANHA, C. Brazil; ALVES, R. C. M. Análise de chuva intensa na Região de Agudo-RS em Janeiro de 2010. In: SIMPÓSIO BRASILEIRO DE SENSORIAMENTO REMOTO - SBSR, 15., 30 de abril a 05 de maio de 2011, Curitiba. Anais... São José dos campos: INPE, 2011.

SILVA, A. E. P.; ANGELIS, C. F.; MACHADO, L, A. T.; WAICHAMAN, A. V. Influência da precipitação na qualidade da água do Rio Purus. Revista Acta Amazônica, v. 38, n. 4, p. 733-742, 2008.

SILVEIRA, J. S. Aspectos hidroclimatológicos da Bacia do Rio Jari no período de 1968 a 2012. Trabalho de Conclusão de Curso (Graduação em Ciências Ambientais) Universidade Federal do Amapá, 2014.

VASCO, A. N.; BRITTO, F. B.; PEREIRA, A. P. S.; MÉLlO JÚNIOR, A. V. M.; GARCIA, C. A. B.; NOGUEIRA, L. C. Avaliação espacial e temporal da qualidade da água na sub-bacia do rio Poxim, Sergipe, Brasil. Revista Ambiente \& Agua. Taubaté, v. 6, n. 1, p. 118-130, 2011. http://dx.doi.org/10.4136/ambi-agua.178

WARD, N. D.; KEIL, R. G.; MEDEIROS, P. M.; BRITO, D. C.; CUNHA, A. C.; DITTMAR, T. et al. Degradation of terrestrially derived macromolecules in the Amazon River. Nature Geoscience, v. 6, n. 6, p. 1-4, 19 maio 2013. http://dx.doi.org/10.1038/ngeo1817 